\title{
Match or Mismatch: Engineering Faculty Beliefs about Communication and Teamwork versus Published Criteria
}

\section{Dr. Marie C Paretti, Virginia Tech}

Marie C. Paretti is an Associate Professor of Engineering Education at Virginia Tech, where she codirects the Virginia Tech Engineering Communications Center (VTECC). Her research focuses on communication in engineering design, interdisciplinary communication and collaboration, design education, and gender in engineering. She was awarded a CAREER grant from the National Science Foundation to study expert teaching in capstone design courses, and is co-PI on numerous NSF grants exploring communication, design, and identity in engineering. Drawing on theories of situated learning and identity development, her work includes studies on the teaching and learning of communication, effective teaching practices in design education, the effects of differing design pedagogies on retention and motivation, the dynamics of cross-disciplinary collaboration in both academic and industry design environments, and gender and identity in engineering.

\section{Ms. Kelly J Cross, Virginia Tech}

Ms. Cross earned her Bachelor of Science in Chemical Engineering from Purdue University in 2007. She earned her Master's of Science in Materials Science and Engineering from the University of Cincinnati in 2011. Ms. Cross is currently in the fourth year of the Engineering Education PhD program at Virginia Tech and involved with multiple educational research projects with faculty and graduate students. Her research interests include teamwork and communication skills, assessment, diversity, and identity construction.

\section{Dr. Holly M Matusovich, Virginia Tech}

Dr. Holly Matusovich (co-PI) is an Assistant Professor in Virginia Tech's Department of Engineering Education. She has her doctorate in Engineering Education and her strengths include qualitative and mixed methods research study design and implementation. Her expertise includes motivation and related frameworks, using these frameworks broadly to study student engagement in learning, student recruitment into and retention within engineering programs and careers, faculty teaching practices and intersections of motivation and learning strategies. 


\title{
Match or Mismatch: Engineering Faculty Beliefs about Communication and Teamwork versus Published Criteria
}

\begin{abstract}
Engineering employers, the National Academy of Engineering (NAE), and the engineering accreditation agency ABET continue to identify communication and teamwork as essential for engineering graduates going into professional practice. The desire for students to enhance these and other professional skills has led to an increase in the number of team projects and communication assignments included within engineering courses. However, educational researchers and educators alike know comparatively little about the beliefs and values of current engineering faculty with respect to communication and teamwork, or about how these faculty epistemologies affect approaches to incorporating and evaluating these skills. To address this gap, this paper analyzes data from interview with engineering faculty in light of published criteria for communication and teamwork. As our benchmark for this initial study, we use the VALUE rubrics developed by the American Association of Colleges and Universities (AACU). Preliminary analysis of a subset of the data suggests areas of both alignment and disparity between engineering faculty and the VALUE rubrics. In particular, engineering faculty beliefs align with the rubrics' emphasis on context and purpose and content development in written communication, but reflect less attention to disciplinary genre conventions and sources. In the teamwork domain, engineering faculty recognize the importance of conflict resolution, but offer few other criteria included in the VALUE rubric. At the same time, faculty emphasize the importance of distributing workload and managing the project effectively, an area not wellrepresented by the rubrics. These findings, once refined through analysis of the full data set, offer areas for faculty development, but also suggest important discipline-specific adaptations of the broad-based VALUE rubrics.
\end{abstract}

\section{Introduction: Why Faculty Beliefs Matter}

Communication and teamwork remain top-priority outcomes for engineering graduates in both academic and industry settings, and they are increasingly integrated into engineering curricula, not only through external course requirements (e.g. technical writing courses), but also within engineering courses. As Shuman et al. ${ }^{1}$ argue in their landmark 2005 review of professional skills, both communication and teamwork can be effectively taught within engineering courses, and engineering education research is rich with discussions of both skills ${ }^{2,3-10}$.

Importantly, both skills have strong pedagogical research bases outside and inside engineering. Work on engineering communication as a domain within English dates back to the late 1800s, and technical communication has developed into an important subfield of writing studies. Moreover, recent engineering education literature contains numerous accounts of courses that address communication skills in engineering contexts. Work on teamwork is more recent, dating back to the 1950s, with more attention focused on the creation and function of effective teams than on the development of team skills in educational environments. Still, the engineering education literature again includes numerous accounts of strategies for incorporating teams into courses (particularly at the capstone level), along with multiple studies of engineering team dynamics. 
Despite the depth of research on both communication and teamwork, what remains unclear is the degree to which engineering faculty engage with and leverage this rich literature. With respect to communication, some researchers have explored differences in feedback patterns between engineering faculty and writing faculty ${ }^{11,12}$ or explored beliefs about writing among disciplinary faculty more generally ${ }^{13,14}$, and the findings suggest both intersections and gaps between faculty with writing expertise and those with expertise in disciplinary content. But little research has considered the relationship between faculty beliefs about effective communication and broadly accepted criteria developed and published by scholars in writing and oral communication. Similarly, although research on assessing teamwork has been increasing in recent years ${ }^{5,15-18}$, little work explores the degree to which faculty accept and/or apply criteria developed by teamwork researchers when teaching and evaluating student performance.

We argue here that identifying both the intersections and the gaps between faculty beliefs and current research with respect to these two core skills is essential if we hope to provide more effective learning environments for students. Only by better understanding what faculty do believe about effective communication and effective teamwork can we more fully support those beliefs that are grounded in empirical research and address gaps or correct misconceptions. To do so, this paper explores the research following research question:

How do faculty beliefs about effective communication and effective teamwork align with empirically based criteria for these two skills?

As a first step toward this question, this paper presents preliminary findings from a larger mixed methods study exploring faculty and student beliefs about teamwork and communication.

\section{Background: What Does "Effective" Mean?}

As suggested above, questions of effectiveness for both communication and teamwork have been explored extensively by scholars from fields such as composition, rhetoric, writing studies, organizational behavior, industrial psychology, and many others. Within the narrower field of engineering education, work such as that by House et al. ${ }^{19}$ provide useful evaluation rubrics for communication, while tools such as the Comprehensive Assessment for Team-Member Effectiveness (CATME) ${ }^{16}$ offer criteria (as well as a web-based tool) for evaluating students' performance on teams.

In both cases, however, these engineering-specific rubrics, are grounded in the broader literature surrounding communication and teamwork, respectively. As a result, in considering a meaningful framework for analyzing faculty beliefs and comparing them to the existing bodies of literature, we turned to a larger national effort focused on the development of assessment rubrics for a range of general education outcomes - the American Association of Colleges and Universities' (AACU) Valid Assessment of Learning in Undergraduate Education (VALUE) project $^{20}$. Focused on outcomes generally associated with liberal education, the VALUE project brought together faculty from AACU member institutions to develop a common set of rubrics for outcomes ranging from civic engagement to integrative learning to reading, including rubrics for oral communication, written communication, and teamwork. Each rubric provides an overall definition for the learning outcome and any key terms, and identifies benchmark, milestone, and capstone performance standards for specific, measurable criteria. Tested across universities and 
disciplines $^{21,22}$, the rubrics provide a useful set of common criteria to begin exploring how the beliefs and expectations of engineering faculty align with larger discussions around communication and teamwork. Table 1 lists the criteria for written communication and teamwork used in this analysis, and provides the definition for "Capstone" achievement, which serves as the preliminary definitions for our analysis (coding).

\section{Table 1: Written Communication and Teamwork Skills Analysis Capstone Achievement Criteria $^{23}$}

\begin{tabular}{|c|c|}
\hline Written Communication & Teamwork \\
\hline $\begin{array}{l}\text { Content and purpose for writing: } \\
\text { Demonstrates a thorough understanding of } \\
\text { context, audience, and purpose that is } \\
\text { responsive to the assigned task(s) and } \\
\text { focuses all elements of the work. } \\
\text { Content development: Uses appropriate, } \\
\text { relevant, and compelling content to illustrate } \\
\text { mastery of the subject, conveying the writer's } \\
\text { understanding, and shaping the whole work. } \\
\text { Genre and disciplinary conventions: } \\
\text { Demonstrates detailed attention to and } \\
\text { successful execution of a wide range of } \\
\text { conventions particular to a specific discipline } \\
\text { and/or writing task (s) including organization, } \\
\text { content, presentation, formatting, and stylistic } \\
\text { choices } \\
\text { Sources and evidence: Demonstrates } \\
\text { skillful use of high-quality, credible, relevant } \\
\text { sources to develop ideas that are appropriate } \\
\text { for the discipline and genre of the writing } \\
\text { Control of syntax and mechanics: Uses } \\
\text { graceful language that skillfully } \\
\text { communicates meaning to readers with } \\
\text { clarity and fluency, and is virtually error-free. }\end{array}$ & $\begin{array}{l}\text { Contributes to team meetings: Helps the team move forward } \\
\text { by articulating the merits of alternative ideas or proposals. } \\
\text { Facilitates the contributions of team members: Engages } \\
\text { team members in ways that facilitate their contributions to } \\
\text { meetings by both constructively building upon or synthesizing } \\
\text { the contributions of others as well as noticing when someone is } \\
\text { not participating and inviting them to engage. } \\
\text { Individual contributions outside of team meetings: } \\
\text { Completes all assigned tasks by deadline; work accomplished is } \\
\text { thorough, comprehensive, and advances the project. Proactively } \\
\text { helps other team members complete their assigned tasks to a } \\
\text { similar level of excellence. } \\
\text { Fosters constructive team climate: Supports a constructive } \\
\text { team climate by doing all of the following: } \\
\text { - Treats team members respectfully by being polite and } \\
\text { constructive in communication. } \\
\text { - Uses positive vocal or written tone, facial expressions, and/or } \\
\text { body language to convey a positive attitude about the team } \\
\text { and its work. } \\
\text { - Motivates teammates by expressing confidence about the } \\
\text { importance of the task and the team's ability to accomplish it. } \\
\text { Provides assistance and/or encouragement to team } \\
\text { members. } \\
\text { and constructively, helping to manage/resolve it in a way that } \\
\text { strengthens overall team cohesiveness and future effectiveness. }\end{array}$ \\
\hline
\end{tabular}

In using the VALUE rubrics as an initial framework, however, we are not suggesting that they capture all of the potentially meaningful criteria or that they offer a definitive statement on "good" communication and teamwork. Indeed, the extensive body of research on writing assessment argues strongly for the need for localization and contextualization of writing rubrics $^{24}$, and similar arguments could be made for both oral communication and teamwork. Despite the limitations of the rubrics, however, they offer one productive starting point for discussion. 


\section{Methods}

Participants

The overall project includes interviews with 50 faculty across five research sites and three engineering disciplines: mechanical, civil, and industrial/systems. In this paper, we present preliminary analysis of 16 of those interviews; analysis of the complete data set is pending at the time of this writing. The interviews used for analysis were randomly selected across all five research sites, which represent a diverse pool of institutional types (e.g. public vs. private, large vs. small, and research vs. teaching). Faculty rank ranged from adjunct or teaching faculty to full professor. Teaching experience ranged from a few years through several years in a variety of context (e.g. academic, industrial, government).

\section{Data Collection and Analysis}

Data collection involved semi-structured interviews with engineering faculty to explore their beliefs about where and how they teach teamwork and communication skills. The interviews were conducted at the five partner school sites over the course of two academic years, between 2011-2013, by four members of a research team. Each interview was audio recorded and transcribed verbatim. Typically, two members of the research team conducted each interview; one led the discussion while the other recorded extensive field notes. We used an a priori coding approach based on the VALUE rubric criteria listed in Table 1 to analyze the data in MAXQDA software. Multiple rounds of coding and debriefing between two members of the research team lead to a list of critical statements and emergent themes, as discussed in the results.

\section{Results: Matches and Mismatches}

Analysis of the subset of 16 randomly selected interviews from the larger pool highlighted areas of both alignment and misalignment between engineering faculty beliefs and the VALUE codes developed by faculty experts. Overall, more criteria associated with communication regularly appeared in faculty comments; faculty responses with respect to effective teamwork skills were generally more limited and showed fewer points of intersection with the VALUE rubrics. The sections below discuss the findings for each rubric.

\section{Communication}

Overall, discussions of written communication showed stronger alignment between faculty beliefs and the VALUE rubrics than teamwork, with four of the five communication-related criteria discussed by at least 10 of the 16 interview participants. Only Sources and Evidence were noted by fewer than half of the participants.

Of the four remaining criteria, the two that emerged most frequently were Context of and Purpose for Writing and Content Development. As suggested by Table 1, the VALUE rubric defines context and purpose in terms of students' ability to consider audience, purpose, and the circumstances surrounding the communication ${ }^{25}$. Such criteria came up routinely as faculty described their beliefs and teaching practices, as illustrated by the following comments (bold typeface is our added emphasis): 
I always say, you have to tune it to the receiver. So if you're transmitting stuff then you have to figure out who you're transmitting information to and then adjust your presentation to that. That's actually one of the things, we got one of our ideals says that, you know is it, it was in senior design, that the other would say, you know, is it appropriate for the audience? ... [T] hey have to use common language, to get the thing, figure out who they're talking to. [Mechanical Engineering Faculty]

[C]ommunication, is, is very much dependent on the content and the audience... Assuming that the person who's delivering those, what they want to say, you know? [Mechanical Engineering Faculty]

They're not telling a story...And so even though we're engineers representing technical issues, you're telling a story. You got to lay out why, you know, "Why is this important to my client? Why did my client come to me?" Basically what [poor-performing students] did was, they explained to me as if they were sitting in front of a room of engineers. ... And we're like, "Okay, no one in your audience understands a word that you just said." [Civil Engineering Faculty]

As these comments suggest, engineering faculty frequently highlight the need language and content directed to the audience with whom you are communicating. And in many cases, participants stressed being able to communicate with a range of technical to non-technical audiences.

The second prominent area of alignment concerned Content Development. The VALUE rubric defines content development in terms of students' ability to "use appropriate, relevant, and compelling content that illustrates mastery of the subject" ${ }^{\prime 25}$, and content that demonstrated students' technical competence was frequently a critical criterion for faculty, as indicated in the following example:

[S]ince it's Engineering, I look for the numbers have to be right, so and with that, are they able to interpret the results appropriately. Because interpretation is probably more important than just dumping excel tables, in a document. So yeah, I look for how they explain the results appropriately.... [A]re they able to infer what the results are saying, instead of just showing the results. [Civil Engineering Faculty]

A number of faculty linked content development specifically to the ability to interpret results rather than "dumping excel tables," as the quote above says.

Content development is, in fact, so critical for faculty that it can outweigh other dimensions of writing, including context and purpose. As one faculty member explains:

[W] hen I do think about audience analysis, it's secondary to coherence and credibility. And they struggle so much with those two things that I, that I tend to downplay audience analysis in all my students' writing, because they're, even as seniors, they're still struggling with, do I believe your result and is this coherent." [Mechanical Engineering Faculty] 
In this example, the faculty member uses the terms "coherence and credibility," where credibility is directly linked to the quality and credibility of the results - echoing the ability to present and interpret results effectively. This faculty member describes students' difficulty in managing the task of analyzing the audience given the range of other communication challenges. In other words, the audience analysis may be secondary to the primary concern with student writing; achieving a coherent and credible conclusion to their calculations or application of a theory.

These findings suggest that while engineering faculty recognize many of the same criteria identified in the VALUE rubric, they may not place equal weight on all criteria. At the same time, the absence of discussions around Sources and Evidence may suggest an important disciplinary adaptation. Because most writing in engineering curricula focuses on students' analysis and interpretation of experimental or design work, the use of external sources may be less central. Faculty interviewed seemed more concerned with how students used their own data as a source, rather than how they integrated external "high quality, credible, relevant sources."

\section{Teamwork}

While faculty discussions of communication showed strong alignment with the criteria identified in the VALUE rubric, far less alignment emerged in the discussions about teamwork. Notably three of the five criteria were mentioned by fewer than half the participants. Only Responds to Conflict and a subset of Fosters Effective Team Climate (respectful behavior) were cited by more than half the participants (11 and 9 individuals, respectively. The one area where faculty consistently agreed with the VALUE criteria was that students should be able to effectively respond to conflict.

You know [conflict is] gonna come. Once I pick the teams I can almost tell you what's gonna come first, this one's gonna have problems right off the bat ... [T] hen I try to help them ... OK... Let's send some emails, or ya know, let's talk, or you know, sit down and talk the issues out. [Civil Engineering Faculty]

As the quote implies, conflict must be addressed proactively and directly, as suggested in the VALUE rubric's metric. But often, discussions of conflict focused on how faculty handle team conflicts, rather than on helping students develop conflict management strategies or evaluating teams based on conflict management. Ironically, although issues related to conflict management surface frequently in these issues, other research also suggests that this is an area where many faculty lack effective strategies for supporting student development. ${ }^{4}$

Importantly, the disparities between faculty beliefs and the VALUE teamwork rubric were not solely about absence. Engineering faculty also frequently cited a criterion not explicitly addressed by the rubric: equitable work distribution and effective team roles - that is, project management. These issues are implicit in the VALUE rubric within Individual Contributions Outside Team Meetings; that criterion includes behaviors such as completing all assigned tasks and helping other team members complete their tasks ${ }^{25}$, which implies a degree of organization and division of labor. While some faculty did cite this individual responsibility, many also emphasized the ways in which the team disturbed the work load, as indicated by the following example: 
[W]e do ask them to be able to - divide up the work among themselves. Not that one person does all the work and the others just sit around. So we ask them like when they start their report to kind of tell us, or discuss with us, the instructors, that you know what is the division of labor in the report there. Who's going to do what and how are they going to communicate with each other? [Mechanical Engineering Faculty]

This and similar comments focus on more on the work load division and less on task completion. This particular issue resonated with a number of engineering faculty as several mentioned the need to monitor workload distribution. For many participants, this ability to organize the project was also linked to the ability to identify team roles, including a team leader:

You know, they can make, maybe divide [the tasks and] identify by volunteering or by natural discussion ... who is the best-suited person in that team to be able to take up that task. And then they should have an open communication between them. And, and they should be able to come up with a designated you know team leader, who's not necessarily there to police them ... but you know only to kind of just remind them of their task or if they're falling behind. This kind of management type .. role in there.. [Engineering Department]

Comments such as this focus on both the ability to organize a team project effectively and the ability to identify and assign critical team roles such as the team leader. The VALUE rubric, in contrast, implies a more of a shared leadership responsibility, with behaviors linked to personal accountability and attention to other team members to ensure overall team success. As with communication, this disconnect between the rubric and engineering faculty beliefs may suggest the need to adapt, and here expand, the rubric to capture components of teamwork that are central to professional engineering practice. In this case, engineering faculty do not appear to expect everyone to be a leader, but rather, to be able to identify the strengths of individual team members and develop reasonable work plans that effectively utilize the team's personnel resources.

\section{Implications and Future Work}

Analysis of a subset of 16 of 50 faculty interviews suggests that while faculty often articulate criteria for effective communication that aligns with national standards, their beliefs show less alignment with criteria for effective teamwork, and in fact, often lack concrete criteria for teamwork altogether. Table 2 summarizes these areas of alignment and divergence. 
Table 2: Areas of Alignment and Divergence

\begin{tabular}{|l|l|l|l|}
\hline & $\begin{array}{l}\text { Match: Engineering Faculty and } \\
\text { VALUE Rubric }\end{array}$ & $\begin{array}{l}\text { Mismatch: VALUE Rubric } \\
\text { Only }\end{array}$ & $\begin{array}{l}\text { Mismatch: Engineering } \\
\text { Faculty Only }\end{array}$ \\
\hline Communication & $\begin{array}{l}\text { Content and purpose for writing } \\
\text { Content development } \\
\text { Genre and disciplinary } \\
\text { conventions } \\
\text { Control of syntax and mechanics }\end{array}$ & Sources and evidence & \\
\hline Teamwork & $\begin{array}{l}\text { Individual contributions outside of } \\
\text { team meetings (partial) } \\
\text { Fosters constructive team climate } \\
\text { (partial) } \\
\text { Responds to conflict }\end{array}$ & $\begin{array}{l}\text { Contributes to team } \\
\text { meetings } \\
\text { Facilitates the } \\
\text { contributions of team } \\
\text { members }\end{array}$ & $\begin{array}{l}\text { Project Management: } \\
\text { Workload distribution and } \\
\text { team roles }\end{array}$ \\
\hline
\end{tabular}

First, the results indicate the engineering faculty's beliefs about effective communication align strongly with the kinds of criteria developed by faculty nationally that reflect current research on communication practices. However, the limited discussion of use of sources and evidence suggests that disciplinary conventions and occasions for writing within engineering may require faculty to adapt the rubrics to more closely match the core professional expectations. At the same time, it may also suggest a writing issue that may be necessary, but not well addressed in engineering curricula currently.

Second, with respect to teamwork, the findings suggest that disciplinary practices highlight issues currently absent from the larger national conversation around teamwork. At the same time, the relative absence of many of the specific VALUE rubric's teamwork criteria may point to an important area for faculty development. Engineering faculty may need more explicit and effective resources to help them both teach and evaluate teamwork practices and thus better support their students' professional development.

As noted, however, these findings represent an analysis of only a portion of the full data set for this project. The next step, currently underway, is the application of these codes to the remaining interviews to test these preliminary findings and develop a more complete picture of engineering faculty beliefs.

\section{Acknowledgement}

This paper is based on research supported by the National Science Foundation under Grant No. EEC-1025189. Any opinions, findings, and conclusions or recommendations expressed in this material are those of the authors and do not necessarily reflect the views of the National Science Foundation. 


\section{References}

1. Shuman, L.J., M. Besterfield-Sacre, and J. McGourty, "The ABET 'Professional Skills' Can They Be Taught? Can They Be Assessed?" Journal of Engineering Education, 2005. 94(1): p. 41-56.

2. Paretti, M.C., et al., "Managing and Mentoring Capstone Design Teams: Considerations and Practices for Faculty." International Journal of Engineering Education, 2011. 27(6): p. 1192-1205.

3. Paretti, M.C., L.D. McNair, and J.A. Leydens, "Engineering Communication," in Cambridge Handbook of Engineering Education Research, A. Johri and B.M. Olds, Editors. 2014 (forthcoming), Cambridge Univ. Press: Cambridge, UK.

4. Paretti, M.C., et al. "Mentoring Team Conflicts in Capstone Design: Problems and Solutions." in 120th American Society for Engineering Education. 2013. Atlanta, GA.

5. Layton, R.A., et al., "Design and Validation of a Web-Based System for Assigning Members to Teams Using Instructor-Specified Criteria." Advances in Engineering Education, 2001. 2(1): p. 1-28.

6. Adams, S.G., "Building successful student teams in the engineering classroom." Journal of STEM Education, 2003. 4(3): p. 4.

7. Craig, J.L., N. Lerner, and M. Poe, "Innovation Across the Curriculum: Three Case Studies in Teaching Science and Engineering Communication." Professional Communication, IEEE Transactions on, 2008. 51(3): p. 280-301.

8. Dannels, D.P., et al. "Integrating Teaming, Writing, and Speaking in CHE Unit Operations Lab." in American Society for Engineering Education Annual Conference and Exposition. 2003. Nashville, TN.

9. Delson, N.J., "Teams and Collaboration - Increasing Team Motivation in Engineering Design Courses." The International journal of engineering education, 2001. 17(4): p. 359 (8 pages).

10. McKenna, A.F. and P. Hirsch. "Evaluating Student Confidence in Engineering Design, Teamwork and Communication." in ASEE Annual Conference and Exposition. 2005. Portland, OR.

11. Smith, S., "What is 'Good' Technical Communication? A Comparison of the Standards of Writing and Engineering Instructors." Technical Communication Quarterly, 2003. 12(1): p. 7-24.

12. Smith, S., "The Role of Technical Expertise in Engineering and Writing Teachers' Evaluations of Students' Writing." Written Communication, 2003. 20(1): p. 37-80.

13. Taylor, S.S. and M.D. Patton, "Ten engineers reading: disjunctions between preference and practice in civil engineering faculty responses." Journal of Technical Writing and Communication, 2006. 36(3): p. 253-271.

14. Thaiss, C. and T.M. Zawacki, Engaged writers and dynamic disciplines: Research on the academic writing life. 2006, Portsmouth: Heinemann.

15. Ohland, M.W. and R.A. Layton. "Comparing the reliability of two peer evaluation instruments." in American Society for Engineering Education Annual Confernce and Exposition. 2000. St. Louis, MO.

16. Loughry, M.L., M.W. Ohland, and D.D. Moore, "Development of a Theory-Based Assessment of Team Member Effectiveness." Educational and Psychological Measurement, 2007. 67(3): p. 505-525. 
17. Davis, D., et al. "Assessments for Three Performance Areas in Capstone Engineering Design." in American Society for Engineering Education Annual Conference and Exposition. 2007. Honolulu, HI.

18. Gentili, K., et al. "Measuring Added-Value Using a Team Design Skills Growth Survey." in American Society for Engineering Education Annual Conference and Exposition. 2005. Portland, OR.

19. House, R., et al., "Assessing Engineering Communication in the Technical Classroom: The Case of Rose-Hulman Institute of Technology," in Assessment of Writing, M.C. Paretti and K. Powell, Editors. 2009, Association of Institutional Research: Tallahassee, FL. p. 127-158.

20. $\quad$ "The VALUE Project Overview." Peer Review, 2009. 11(1): p. 4-7.

21. Finley, A.P., "How Reliable Are the VALUE Rubrics?" Peer Review, 2011. 13/14(4/1): p. 31-33.

22. Rhodes, T.L., "Emerging Evidence on Using Rubrics." Peer Review, 2011. 13/14(4/1): p. 4-5.

23. Association of American Colleges and Universities, "Liberal Education Outcomes: A Preliminary Report on Student Achievement in College." 2005, Association of American Colleges and Universities: Washtington, D.C. p. 20 pp.

24. Paretti, M.C. and K.M. Powell, "Introduction: Bringing Voices Together: Partnerships for Assessing Writing Across Contexts," in Assessment of Writing, M.C. Paretti and K. Powell, Editors. 2009, Association of Institutional Research: Tallahassee, FL. p. 1-10.

25. Rhodes, T.L. and L. Education, Assessing outcomes and improving achievement: Tips and tools for using rubrics. 2010: Association of American Colleges and Universities. 